\title{
IN VITRO EVALUATION OF THE ANTHELMINTIC ACTIVITY OF RHIZOME EXTRACTS OF CURCUMA LONGA (LINN.)
}

\author{
JYOTI PANDEY, SUMAN MISHRA, KAMAL JAISWAL
}

Department of Zoology, Babasaheb Bhimrao Ambedkar University, Lucknow, Uttar Pradesh, India. Email: drkamaljaiswal@gmail.com Received: 07 July 2018, Revised and Accepted: 15 August 2018

\begin{abstract}
Objective: The current study was carried out to evaluate the anthelmintic activity of the rhizome extract of Curcuma longa as an alternative source of effective remedies for nematodiasis.

Methods: The anthelmintic activity of the C. longa was assessed in vitro against Haemonchus spp., a gastrointestinal (abomasum) parasite of goats. Different concentrations of the extracts $(1 \mathrm{mg} / \mathrm{mL}, 2.5 \mathrm{mg} / \mathrm{mL}, 5 \mathrm{mg} / \mathrm{mL}$, and $10 \mathrm{mg} / \mathrm{mL}$ ) in phosphate-buffered saline (PBS) were tested, and the results expressed in terms of time of paralysis (minute) and time of death (minute) of the worms. Albendazole (1 mg/mL) was used as a reference (positive control) and PBS as a control group (negative control).

Results: The qualitative phytochemical analysis of the methanolic extract (ME) of the plant disclosed the presence of alkaloids, glycosides, terpenoids, flavonoids, tannins, saponins, phenol, anthraquinone, and carbohydrates; whereas, the aqueous extract (AE) showed the presence of alkaloids, carbohydrate, flavonoids, and saponins. Both ME and AE of the $C$. longa (rhizome) expressed significant efficacy (p $\leq 0.05$ ) in causing paralysis as well as the death of the worms within $12 \mathrm{~h}$ of exposure at all tested concentrations, as compared to the negative control. The rhizome extracts of $C$. longa showed dose-dependent efficacy in causing paralysis of the worm motility and the final progression to death. The results showed that the ME at $10 \mathrm{mg} / \mathrm{mL}$ was significantly more potent $(\mathrm{p} \leq 0.05)$ over the AE.
\end{abstract}

Conclusions: This study concluded that the rhizome extract of $C$. longa exhibited potent anthelmintic efficacy against the nematode parasite, Haemonchus spp.

Keywords: Anthelmintic activity, Curcuma longa, Nematodiasis, Haemonchus spp., Albendazole.

(C) 2018 The Authors. Published by Innovare Academic Sciences Pvt Ltd. This is an open access article under the CC BY license (http://creativecommons. org/licenses/by/4. 0/) DOI: http://dx.doi.org/10.22159/ajpcr.2018.v11i12.28313

\section{INTRODUCTION}

Haemonchosis has been recognized as a serious constraint to the small ruminants throughout the world [1] and has also been reported from several states of India, namely Himachal Pradesh, Punjab, and Uttarakhand [2-4]. Due to the high prevalence rate, ubiquitous distribution and serious pathological consequences, these parasites have been responsible for massive economic losses to the rural farmers and livestock industry [5]. These parasites are associated with severe damage to the host in several ways including extensive damage to the intestinal wall and sucking of host blood and nutrients. Prolonged infections may result in hypoproteinemia, gauntness, anorexia, diarrhea, edema, and high mortality rate in affected animals [6].

Rid of the infections from grazing animals is complicated due to variations in the host propensity to the parasite and its cosmopolitan nature. To control haemonchosis, farmers, generally, use modern synthetic drugs as anthelmintic, in combination with proper grazing management practices. Synthetic anthelmintics, till date, are repeatedly used to evict parasitic helminths from the host body by killing [7], however, due to high cost and inadequate availability; these drugs are off limits to the resource-poor farmers of the developing countries [8]. Furthermore, unfortunately, due to imprudent and frequent use of these drugs, their effectiveness is continuously decreasing, and in the past few years, the parasites not only have developed resistance against the available anthelmintics, but their chemical residue and toxicity have also become a severe problem, the world over [9].

In view of the above, it was found imperative to look for alternatives that may be developed as sustainable, safer, and environmentally friendly anthelmintic [10], and for these reasons, there has been a renewed interest in the screening of traditionally used therapeutic plants in search of their anthelmintic properties.

Curcuma longa Linn. (turmeric) belongs to the family Zingiberaceae and is usually known as "Haldi." It is a perennial herb having tuberous roots and short stem with large leaves, being widely cultivated in India, Indonesia, Bangladesh, France, and other Asian countries. The turmeric plant shows medicinal properties and contains phytochemical constituents such as essential oil, alkaloid, starch grain, and curcumin (a polyphenol) [11]. Since ancient times, C. longa has been used as a herbal medicine for different therapeutic purposes [12] and some previous studies have reported the positive effects of $C$. longa in the treatment of cancers, heart disease, and soreness [13]. Extract of $C$. longa has also been established for antiparasitic activities against leishmaniasis, hydatidosis, giardiasis, trypanosomiasis, and schistosomiasis [14]. C. longa successfully worked as an anthelmintic against Ascaridia galli both in vitro and in vivo [15], Haemonchus spp. of sheep in vitro [16], and Fasciola gigantica [17]. Based on the traditional uses and scientific reports, the objective of the present study was to evaluate the anthelmintic activity of the rhizome extract of $C$. longa using the gastrointestinal (GI) nematode parasite of the goat, Haemonchus spp. as a model.

\section{METHODS}

In vitro analysis was conducted to evaluate the anthelmintic potential of aqueous extract (AE) and methanolic extract (ME) of rhizome of C. longa against Haemonchus spp. of the goat. Albendazole was used as reference drug for the assay. The study was carried out at the Parasitology and Silkworm Pathology Laboratory of the Department of Zoology (formerly the Department of Applied Animal Sciences) 
Babasaheb Bhimrao Ambedkar University (B. B. A. U.), Lucknow, Uttar Pradesh.

\section{Collection of plant material and preparation of extracts}

Rhizomes of $C$. longa were purchased from the local markets in Lucknow and authenticated in the Department of Applied Plant Sciences of the University. The rhizomes were washed carefully in running water, cut into small pieces, and shade dried for 2-3 weeks under room temperature. Finally, it was ground to a fine powder with the help of electric grinder before further processing: $100 \mathrm{~g}$ of fine powder of the rhizomes was subjected to extraction in Soxhlet apparatus using $500 \mathrm{~mL}$ each of water and methanol separately, as solvents, for $48 \mathrm{~h}$ at room temperature. The respective extracts were concentrated by evaporation in the water bath and then dried in open air and stored in air-tight containers at $4{ }^{\circ} \mathrm{C}$ until further use $[18,19]$.

\section{PRELIMINARY PHYTOCHEMICAL SCREENING}

Phytochemical analysis was carried out on the $C$. longa rhizome extract, and the results revealed the existence of various biological active compounds such as tannins, saponins, alkaloids, flavonoids, glycosides, terpenoids, phenol, carbohydrates, and anthraquinone [8,20-24].

\section{Test organism}

Adult nematode parasitic worms of Haemonchus spp., collected from the GI tracts of goats, were used for all the trial protocols. Briefly, the method of collection of the parasites from the GI tract of goats is as follows: GI tracts of goats were collected from the slaughterhouses in the Lucknow region and immediately transported to the Parasitology Laboratory of the Department of Zoology (formerly the Department of Applied Animal Sciences) B.B.A.U., Lucknow. The GI tracts were dissected following standard procedure and examined for the presence of Haemonchus spp. worms. Adult worms were collected from the abomasum of the GI tract of the goat, washed with normal saline, and kept in phosphate-buffered saline (PBS, pH - 7.5-8.0) until further use in the anthelmintic activity assays.

\section{In vitro anthelmintic activity}

The anthelmintic activity of the AE and ME of C. longa was carried out by following the standard protocol $[16,25,26]$ with some minor modifications. All the working solutions were freshly prepared before the start of the experiment. 10 actively moving, equal sized worms were placed in Petri dishes at room temperature $\left(25^{\circ} \mathrm{C}-30^{\circ} \mathrm{C}\right)$ containing $1 \mathrm{mg} / \mathrm{mL}, 2.5 \mathrm{mg} / \mathrm{mL}, 5 \mathrm{mg} / \mathrm{mL}$, and $10 \mathrm{mg} / \mathrm{mL}$ of AE and ME of the Curcuma rhizome, respectively, in PBS. Positive and negative controls were simultaneously set up with Albendazole and PBS, respectively.
Three replicates were set for each concentration and observations were made at $1,2,3,4,5,6,7$, and $12 \mathrm{~h}$ of the time taken to get paralyzed and finally die for all the worms. After each interval of time, the paralyzed worms were placed in PBS for $30 \mathrm{~min}$ for possible recovery of the parasite motility. After $12 \mathrm{~h}$, from each of the experimental groups, the respective extract concentration solution was discarded and the number of alive and dead worms in each concentration was counted under a dissecting microscope and recorded. The worms were counted, as dead when they lost their motility permanently and did not recover even after placing in PBS. The loss of motility or paralysis was supposed to occur when the worms were not able to move even after placing in the PBS. Paralysis was followed by fading away of the body color of the dead worm $[25,27,28]$.

\section{Statistical analysis}

The results are expressed as mean \pm S.E.M of 10 worms for each concentration level in the treatment regimen. The statistical analysis was done using one-way ANOVA (SPSS version 20.00) followed by Tukey post hoc test. The level of significance was set at $\mathrm{p}<0.05$.

\section{RESULTS}

In the present study, the phytochemical analysis of the $C$. longa rhizome extracts, both ME and AE, was carried out, and the results are shown in Table 1. In the screening analysis, different types of results have been observed in the methanolic and aqueous solvents, i.e., ME showed the presence of glycosides, alkaloids, flavonoids, tannins, saponins, terpenoids, phenol, anthraquinone, and carbohydrates while the $\mathrm{AE}$ showed the presence of alkaloids, carbohydrate, flavonoids, terpenoids, and saponins.

The anthelmintic activity of the ME and $\mathrm{AE}$ of the rhizome of $C$. longa and evaluated in vitro against Haemonchus spp., the abomasal nematode parasite of goat, and the results are shown in Table 2, Figs. 1 and 2. The results revealed that both the $\mathrm{AE}$ and $\mathrm{ME}$ of the plant exhibited significant $(p \leq 0.05)$ efficacy in causing paralysis as well as the death of the worms at all the tested concentrations (Table 2, Figs. 1 and 2). At the concentration of $1 \mathrm{mg} / \mathrm{mL}, \mathrm{ME}$ of $C$. longa caused paralysis followed by the death of the worm's in $139.0 \pm 0.6 \mathrm{~min}$ and $175.3 \pm 2.0 \mathrm{~min}$, respectively; while, at $2.5 \mathrm{mg} / \mathrm{mL}$ concentration, paralysis and death occurred at $120.0 \pm 1.1 \mathrm{~min}$ and $160.7 \pm 1.8 \mathrm{~min}$, respectively. However, at the $5 \mathrm{mg} / \mathrm{mL}$ of concentration, the time taken for paralysis of the worms was $100.3 \pm 0.9 \mathrm{~min}$ while death occurred at $147.7 \pm 3.5 \mathrm{~min}$. The most proficient anthelmintic activity was exhibited at the concentration of $10 \mathrm{mg} / \mathrm{mL}$ at least time was taken for paralysis and finally death of the worms at $66.0 \pm 1.5 \mathrm{~min}$ and $96.0 \pm 2.1 \mathrm{~min}$, respectively. Similar

Table 1: Preliminary phytochemical screening of aqueous and methanolic rhizome extracts of $C$. longa

\begin{tabular}{|c|c|c|c|c|}
\hline Test & Procedure & Observation & $\mathbf{A E}$ & ME \\
\hline Alkaloids & Mayer's test & Cream/off-white color Ppt & + & + \\
\hline Flavonoids & Alkaline reagent test & Yellow color & + & + \\
\hline Glycosides & $\begin{array}{l}\mathrm{ZnCl}_{2} \text { test } \\
\text { Extract+dil. } \mathrm{H}_{2} \mathrm{SO}_{4} \Rightarrow \text { Boiled then } \\
\text { Cooled+solution of } \mathrm{NaOH}+\text { Fehling's solution } \mathrm{A} \text { and } \mathrm{B} \text {, heat } \\
\text { on the water bath }\end{array}$ & $\begin{array}{l}\text { Red color } \\
\text { Brick red Ppt }\end{array}$ & - & + \\
\hline Terpenoids & Salkowski's test & Yellow color & + & ++ \\
\hline Saponins & Foam test & $\begin{array}{l}\text { Formation of } \\
\text { honeycomb-like } \\
\text { structure (Forth) }\end{array}$ & + & ++ \\
\hline Phenol & $\mathrm{FeCl}_{3}$ test & $\begin{array}{l}\text { Blue-green } \\
\text { color }\end{array}$ & - & + \\
\hline Carbohydrates & Benedict's test & Red Ppt & + & ++ \\
\hline & Fehling's test & Red Ppt & + & ++ \\
\hline
\end{tabular}

-Not detected, +low concentration, ++high concentration, Ppt - precipitate. C. longa: Curcuma longa, AE: Aqueous extract, ME: Methanolic extract 
Table 2: In vitro anthelmintic assay of AE and ME of rhizome of $C$. longa against Haemonchus spp.

\begin{tabular}{llll}
\hline Treatment & Concentration $(\mathrm{mg} / \mathbf{m L})$ & Paralysis time $(\mathbf{m i n})(\mathbf{m e a n} \pm$ SEM) & Death time $(\mathbf{m i n})(\mathbf{m e a n} \pm \mathbf{S E M})$ \\
\hline Control & - & 0.0 & 0.0 \\
Albendazole & 1 & $32 \pm 2.3^{*}$ & $57.3 \pm 5.5^{*}$ \\
C. longa (AE) & 1 & $159.7 \pm 2.0^{*}$ & $198.0 \pm 2.5^{*}$ \\
& 2.5 & $140.0 \pm 1.1^{*}$ & $178.7 \pm 1.9^{*}$ \\
& 5 & $109.3 \pm 1.8^{*}$ & $154.3 \pm 1.2^{*}$ \\
C. longa (ME) & 10 & $83.3 \pm 0.9^{*}$ & $119.0 . \pm 2.6^{*}$ \\
& 1 & $139.0 \pm 0.6^{*}$ & $175.3 \pm 2.0^{*}$ \\
& 2.5 & $120.0 \pm 1.1^{*}$ & $160.7 \pm 1.8^{*}$ \\
& 5 & $100.3 \pm 0.9^{*}$ & $147.7 \pm 3.5^{*}$ \\
\hline
\end{tabular}

Values are mean \pm SEM, $(\mathrm{n}=10),{ }^{*} \mathrm{p} \leq 0.05$ as compared to control group (one-way ANOVA followed by Tukey post hoc test), (p $\left.>0.05\right)$. AE: Aqueous extract, ME: Methanolic extract, C. longa: Curcuma longa

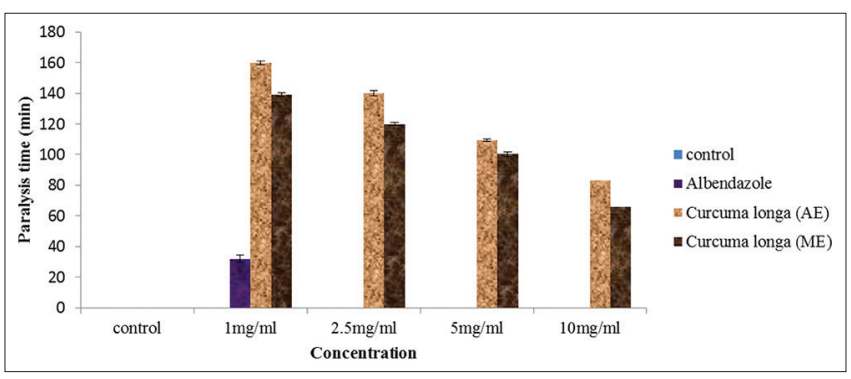

Fig. 1: Anthelmintic assay (worm paralysis) of aqueous extract and methanolic extract of Curcuma longa rhizome as compared to standard drug (albendazole)

dose-dependent anthelmintic efficacy was shown by the $\mathrm{AE}$ of $C$. longa, wherein it took $159.7 \pm 2.0 \mathrm{~min}$ for paralysis and $198.0 \pm 2.5 \mathrm{~min}$ for the death of the parasite in the concentration of $1 \mathrm{mg} / \mathrm{mL}$. At $2.5 \mathrm{mg} / \mathrm{mL}$ concentration of AE, the time of paralysis and death was $140.0 \pm 1.1 \mathrm{~min}$ and $178.7 \pm 1.9 \mathrm{~min}$, respectively. For the concentration of $5 \mathrm{mg} / \mathrm{mL}$, worms got paralyzed at $109.3 \pm 1.8 \mathrm{~min}$ and died at $154.3 \pm 1.2 \mathrm{~min}$. Similar to the efficacy of ME, the $\mathrm{AE}$ at $10 \mathrm{mg} / \mathrm{mL}$ concentration proved to be most effective, causing paralysis at $83.3 \pm 0.9 \mathrm{~min}$ and death at $119.0 \pm 2.6 \mathrm{~min}$. In the negative control (PBS) group, the worms were found to be efficiently motile and showed no paralysis or death within the $12 \mathrm{~h}$ study period. The positive control (albendazole) at the concentration of $1 \mathrm{mg} / \mathrm{mL}$ was very effective, causing paralysis at $32.0 \pm 2.3 \mathrm{~min}$ and death at $57.3 \pm 5.5 \mathrm{~min}$.

\section{DISCUSSION}

Ethnoveterinary plants are the natural source for various types of the bioactive compound having the plentiful biological characteristic as medicine or for nourishment [29]. The present study demonstrated that the both $\mathrm{AE}$ and $\mathrm{ME}$ of $C$. longa have significant anthelmintic activity against Haemonchus spp. in vitro. The principal effect of the synthetic anthelmintic drug on the worm, as reported by other authors also, was to cause a drooping paralysis that results in the eviction of the worm by peristalsis. The high efficacy of standard drug albendazole is attributed to the action that it probably blocks the glucose uptake (by binding itself to free protein in the intestinal tract or on the body surface) which leads to reduced glycogen level in the parasite and finally resulting in occurrence of the death of the worms [30].

The qualitative phytochemical screening of the plant revealed the presence of secondary metabolites having great medicinal value as well as biological significance [31]. Several earlier studies have revealed that the anthelmintic activity of the plant is due to their phytochemical constituents', namely tannins, saponins, alkaloids, and phenols [22,32]. Tannins could bind to the cuticle of the worm body surface, causing paralysis and leading to death [9]. Alkaloids have antioxidating properties, hence, reduce nitrate generation which is used for protein synthesis, obstruct the transfer of sucrose from the stomach to the

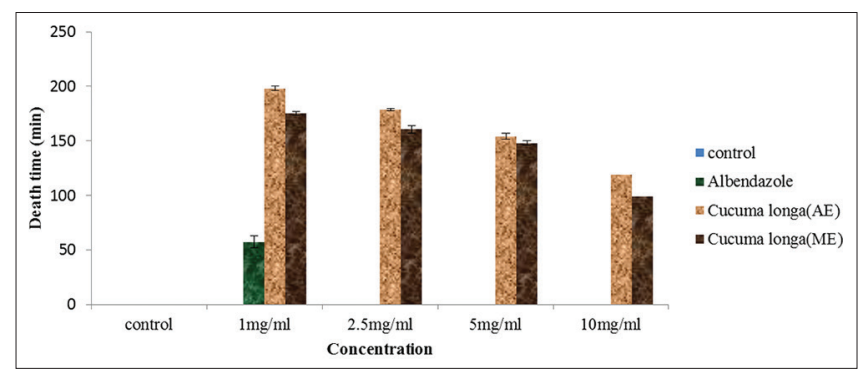

Fig. 2: Anthelmintic assay (worm death) of aqueous extract and methanolic extract of Curcuma longa as compared to standard drug (albendazole)

small intestine, and fail to support glucose uptake to the helminths that effects on CNS causing paralysis [33]. Saponin leads to vocalization and breakdown of helminths cuticular surface [34]. A number of allopathic phenolic anthelmintics such as niclosamide and bithionol are shown to hinder the path of energy generated in helminth parasites as a result of uncoupling oxidative phosphorylation, and this process probably supported the anthelmintic potency of tannins which is responsible for blocking ATP synthesis in these parasites [35].

The current study revealed that the ME showed the presence of glycosides, alkaloids, flavonoids, tannins, saponins, terpenoids, phenol, anthraquinone, and carbohydrates similar results were reported by other researchers $[24,36]$, while the $\mathrm{AE}$ showed the presence of alkaloids, carbohydrate, flavonoids, terpenoids, and saponins which was similarly observed by other workers [37]. The results also disclosed that both $\mathrm{AE}$ and ME showed dose-dependent efficacy toward the paralysis of worms, which finally progressed to death as compared to the reference drug albendazole (positive control). Similar results were observed by studying other medicinal plants [38,39]. In the present study, the results shown that the ME of the plant rhizome at $10 \mathrm{mg} / \mathrm{mL}$ showed significantly higher potency $(p \leq 0.05)$ toward the anthelmintic activity in comparison to the $\mathrm{AE}$ at the same concentration. The reason for this difference might be due to the presence of higher concentrations of biologically active compounds, i.e., tannins, saponins, phenols, and alkaloids in the ME of $C$. longa as compared to the AE. Similar findings have also been reported by other researchers with different ethnoveterinary plants [40-42]. Eventually, the outcomes of this study must be authenticated with in vivo analysis to evaluate the actual anthelmintic potency of this plant and could provide cheap and safe anthelmintic herbal drug.

\section{CONCLUSION}

The present study revealed that although both the $\mathrm{AE}$ and ME of C. longa showed dose-dependent anthelmintic activity in vitro against the Haemonchus spp. of GI parasite of goat, the ME possessed better anthelmintic efficacy. Both extracts of the plant rhizome (ME and AE) were screened for preliminary (qualitative) phytochemical analysis 
and found to possess various types of secondary metabolites, especially tannins, saponins, phenols, and alkaloids which are reported to be responsible for the antiparasitic activity [43]. Thus, it is concluded from the present study that the extracts of $C$. longa could be explored further in the development of anthelmintic lead to treat parasitic diseases such as nematodiasis. The plant needs to be extensively studied in depth further for isolating the active component showing antiparasitic activity and for evaluating its potential for providing an alternative economical remedy resource so that common people can obtain the actual benefit of this important indigenous medicinal plant.

\section{ACKNOWLEDGMENT}

The author (Jyoti Pandey) is thankful to UGC for the non-NET research fellowship.

\section{AUTHOR'S CONTRIBUTIONS}

Mrs. Jyoti Pandey contributed in carrying out the research, data compilation, and wrote the article. Dr. Kamal Jaiswal and Dr. Suman Mishra both were involved in corrections in the article and experimental set up of the study.

\section{CONFLICTS OF INTEREST}

The authors declare that this article has no conflicts of interest.

\section{REFERENCES}

1. Perry BD, Randolph TF, McDermott JJ, Sones KR, Thornton PK. Investing in Animal Health Research to Alleviate Poverty. Nairobi: International Livestock Research Institute; 2002. p. 148.

2. Katoch R, Mandial RK, Nagal KB. Outbreak of Haemonchus contortus infection in sheep of Himachal Pradesh. Indian Vet J 1999;76:932-3.

3. Kaur H, Kaur D. Prevalence of gastrointestinal parasites in domestic animals of Patiala and its adjoining areas. J Vet Parasitol 2008;22:25-8.

4. Yadav CL, Rajeev RK, Banerjee PS, Godara R, Garg R, Vatsya S. Epidemiology of gastro-intestinal nematodes in sheep. Indian Vet $\mathrm{J}$ 2009;86:1010-3

5. Coop RL, Holms PH. Nutrition and parasite interaction. Intern $\mathbf{J}$ Parasitol 1996;26:951-62.

6. Githigia SM, Thamsborg SM, Munyua WK, Maingi N. Impact of gastrointestinal helminths on production in goats in Kenya. Small Rumin Res 2001;42:21-9.

7. Chaturvedi M, Dwivedi S, Dwivedi A, Barpete PK, Sachan R. Formulation and evaluation of polyherbal anthelmintic preparation. Ethnobot Leaflet 2009;13:329-31.

8. Trease GE, Evans WC. A Textbook of Pharmacognosy. $12^{\text {th }}$ ed. London: Bailliere Tindal Ltd.; 1989. p. 374-726.

9. Thompson P, Geary TG. The Structure and Function of Helminth Surfaces. In: Biochemistry and Molecular Biology of Parasites. $1^{\text {th }}$ ed. New York: Academic Press; 1995. p. 203-32.

10. Akhtar MS, Zafar I, Khan MN, Muhammad L. Anthelmintic activity of medicinal plants with particular reference to their use in animals in Indo-Pakistan subcontinent. Small Rumin Res 2000;8:99-107.

11. Singh R, Mehta A, Mehta P, Shukla K. Anthelmintic activity of rhizome extracts of Curcuma longa and Zingiber officinale (Zingiberaceae). Int J Pharm Pharm Sci 2011;3:236-7.

12. Maheshwari RK, Singh AK, Gaddipati J, Srimal RC. Multiple biological activities of curcumin: A short review. Life Sci 2006;78:2081-7.

13. Akram M, Udin S, Ahmed A,Usmanghani K, Hanan A, Mohiudin E, et al. Curcuma longa and curcumin: A review article. Rom J Biol Plant Biol 2010;5:65-70

14. Morais ER, Oliveira KC, Magalhaes LG, Moreira EB, VerjovskiAlmeida S, RodriguesV. Effects of curcumin on the parasite Schistosoma mansoni: A transcriptomic approach. Mol Biochem Parasitol 2013;187:91-7.

15. Bazh EK, El-BahyNM. In vitro and in vivo screening of anthelmintic activity of ginger and curcumin on Ascaridia galli. Parasitol Res 2013;112:3679-86.

16. Ullah S, Khan MN, Sajid MS, Muhammad G. Comparative anthelmintic efficacy of Curcuma longa, Citrullus colocynthis and Peganum harmala. Glob Vet 2013;11:560-7.

17. Ullah R, Rehman A, Zafeer F, Rehman L, Khan YA, Khan MA, et al. Anthelmintic potential of thymoquinone and curcumin on Fasciola gigantica. PLoS One 2017;12:e0171267.

18. Sermakkani M, Thangapandian V. Phytochemical screening for active compounds in Pedalium murex. Recent Res Sci Tech 2010;2:110-4.

19. Khyade M, Kasote D, Kshirsagar S, Gaikwad J, Bharati K. Anthelmintic screening of some plants used in traditional medicine. Asian J Biomed Pharma Sci 2012;2: 516-22.

20. Harborne JB. Phytochemical Methods. A Guide to Modern Techniques of Plant Analysis. London, New York: Chapman and Hall Ltd.; 1973. p. 279.

21. Sofowora A. Medical Plants and Traditional Medicine in Africa. $2^{\text {nd }}$ ed. Ibadan, Nigeria: Spectrum Books Ltd.; 1993. p. 71-3.

22. Wang JF, Zhao LW, Li J. In vivo anthelmintic activity of five alkaloids from Macleaya microcarpa (Maxim) fedde against Dactylogyrus intermedius in Carassius auratus. Vet Parasitol 2010;171:305-13.

23. Hegde K, Joshi AB. Scholars research library. Der Pharm Lett 2010;2:255.

24. Sawant RS, Godghate AG. Qualitative phytochemical screening of rhizomes of Curcuma longa Linn. Int J Sci Environ Technol 2013:2;634-41

25. Dash GK, Suresh P, Kar DM, Ganpaty S, Panda SB. Evaluation of evolvulus alsinoids linn for anthelmintic and antimicrobial activities. J Nat Rem 2002;2:182-5.

26. Eguale T, Tilahun G, Debella A, Feleke A, Makonnen E. Haemonchus contortus: In vitro and in vivo anthelmintic activity of aqueous and hydroalcoholic extracts of Hedera helix. Exper Parasito 2007;116:340-5.

27. Iqbal Z, Nadeem $\mathrm{QK}$, Khan MN, Akhtar MS, Waraich FN. In vitro anthelmintic activity of Allium sativum, Zingiber officinale, Curcurbita mexicana and Ficus religiosa. Int J Agric Biol 2001;3:454-7.

28. Ghosh T, Maity TK, Bose A, Dash GK. Anthelmintic activity of Bacopa monierri. Indian J Nat Prodet 2005;21:16-19.

29. Swargiary A, Nath P, Basumatary B, Brahma D. Phytochemical, antioxidant, and trace element analysis of anthelmintic plants of NorthEast India. Int J Pharm Pharm Sci 2017;9:228-32.

30. Parvathy NG, Padma R, Renjith V, Kalpana PR, Saranya TS. Phytochemical screening and anthelmintic activity of methanolic extract Ofimperata cylindrica. In J Pharma Pharma Sci 2012;4: 232-4.

31. Kumar AK, chandrashekar KR. Phytochemical evaluation and in vitro antimicrobial and antioxidant studies of leaf and stem bark extracts of Polyalthia fragrans (dalz) bedd-an endemic species of Western Ghats. Int J Pharm Pharm Sci 2017:9;20-4.

32. Anthnasiadou S, Kyriazakis I, Jackson F, Coop RL. Direct anthelmintic effects of condensed tannins towards different gastrointestinal nematodes of sheep: In vitro and in vivo studies. Vet Parasitol 2000;99:205-19.

33. Srivastav R, Pathak V, Tripathi IP. Comparative phytochemical and physicochemical study of tulsi (Ocimum sanctum) and haldi (Curcuma longa). In J Pharm Bio Arch 2018;9:55-7.

34. Roy H, Chakroborty A, Bhanja S, Nayak BS, Mishra SR, Ellaiah P. Preliminary phytochemical investigation and anthelmintic activity of Acanthospermum hispidum DC. J Pharma Sci Tech 2010;2:217-21.

35. Tiwari P, Kumar B, Kaur M, Kaur G, Kaur H. Phytochemical screening and extraction: A review. Pharm Sci 2011;1:98-106

36. Martin RJ. Modes of action of antihelmentic drugs. Vet J 1997;154:11-34.

37. Rajesh H, Rao SN, Rani NM, Shetty PK, Rejeesh EP, Chandrashekar R. Phytochemical analysis of methanolic extract of Curcuma longa linn rhizome. In J Uni Pharm Bio Sci 2013;2: 39-45.

38. Kane SR, Mohite SK, Shete JS. Antihelmintic activity of aqueous and methanolic extracts of Euphorbia thymifolia Linn. In J Pharm Tech Res 2009; $1: 666-9$.

39. De S, Dey A, Babu AM, Aneela S. In vitro anthelmintic activity of aqueous and methanolic extracts of Oldenlandia umbellate. Int J Pharm Pharm Sci 2014;6:94-5.

40. Iqbal Z, Sarwar M, Jabbar A, Ahmed S, Nisa M, Sajid MS et al. Direct and indirect anthelmintic effects of condensed tannins in sheep. Vet Parasito 2007; 144:125-31.

41. Bharathi NM, Sravanthi V, Sujeeth S, Kalpana K, Santhoshi. P, et al. In-vitro anthelmintic activity of methanolic and aqueous extracts of Achyranthes aspera Linn. (Amaranthaceae) Stems. J Pharm Sci 2013;3:181-4

42. Bashir AL, Chishti MZ, Bhat FA, Tak H, Bandh SA, Khan A. Anthelmintic activities of aqueous and methanol extracts of Prunella vulgaris L. Nat Prod Chem Res 2017;5:4

43. Debella A. Manual for Phytochemical Screening of Medicinal Plants. Addis Ababa, Ethiopia: Ethiopian Health and Nutrition Research Institute; 2002 